\title{
Em tôrno da questão "Deficiências Minerais em Sisal e a Necrose da Base das Fôlhas"
}

\author{
TUFI COURY \\ Livre Docente e $1^{\circ}$. Assistente da $2^{2}$. Cadeira \\ Chefe da Secção de "Química Agrícola" \\ Escola Superior de Agricultura "Luiz de Queiroz" \\ Universidade de São Paulo
}

Comunicação feita à 3a. Reunião Brasileira de Ciência do Solo realizada em Recife de 17 a 29 de Julho de 1951. 
O autor da presente comunicação vem procedendo a ensaios de adubação mineral e orgânica, além de uma experiência de competição de adubos potássicos, na Secção Técnica "Química Agrícola", da Escola Superior de Agricultura "Luiz de Queiroz", da Universidade de São Paulo (em colaboração com os demais assistentes da 2a. Cadeira, com o Dr. Frederico Pimentel Gomes, Livre Docente de Matemática e ainda com o Dr. V. L. Fagundes, da Secção de Fibras do Departamento do Fomento de Produção Vegetal da Secretaria da Agricultura do Estado de São Paulo) com sisal, desde 1944; os resultados parciais são objeto de apreciação em nota prévia a ser apresentada em Outubro vindouro no II Congresso Mundial de Adubos Químicos, a ser realizado em Roma.

Portanto, há 7 anos vem lidando em ensaios com fertilizantes nesta importante cultura da melhor fibra dura que já existiu e cuja produção mundial é de mais da metade do total das fibras dêsse tipo. O Brasil, que há 8 anós atrás importava fibras para atender às suas necessidades, hoje exporta um excedente apreciável, canalizando divisas para o Tesouro Nacional. No longo contacto com o sisal, tem feito uma série de observações interessantes, não só no tocante à parte cultural, como na adubação, moléstias, corte, espaçamento, enviveiramento, desfibramento, etc. Nestas condições, tendo lido o trabalho de Paulo de T. Alvim "Deficiências minerais em sisal e a necrose da base das folhas". Separata da Revista "Ceres" Vol. VIII - Janeiro-Junho - 1950 - N. 46 - Viçosa - Minas, que afirma que "a doença conhecida como necrose da base das folhas" não parece ser causada por falta de potássio no solo e sim por carência de magnésio, discorda inteiramente dêsse ponto de vista, continuando a julgar ser a falta de potássio o responsável pelo aparecimento do "colarinho preto" ou, como chamam os ingleses, "banding disease", "leaf foot disease" ou, ainda, "leaf basal necrose", como, aliás, pensam Medina, Morstalt, Doop, Staner, Verplancke e outros.

O referido trabalho foi apresentado à 1a. Reunião da Sociedade Botânica do Brasil, em Janeiro de 1950; fazendo justiça ao autor do trabalho, o Dr. Alvim, devo dizer que o ensaio foi muito bem delineado, com tôda a moderna técnica de experimentação em solução nutritiva, com tôdas as determinações necessárias, lidando-se, ademais, com ausência de importantes elementos nutritivos $\mathrm{P}-\mathrm{K}-\mathrm{N}-\mathrm{Mg}-\mathrm{Fe}$ e ainda $\mathrm{B}$ (iniciou com calcio, porém abandonou posteriormente por motivos justos) e com tudo mais. Entretanto, segundo a nossa opinião, na solução sem magnésio houve necrose, porém, uma necrose “qual- 
quer", que sucede nas folhas das plantas cloróticas por falta de um elemento útil (N-Fe-S-Mg, etc.) e não a necrose basal típica. E' sabido que sem $\mathrm{Mg}$ não há clorofila e a reserva de $\mathrm{Mg}$ contida nos bulbilhos foi insuficiente para fornecer clorofila suficiente às folhas, determinando a necrose "qualquer" observada. Releva notar, aqui, que as necessidades de $\mathrm{Mg}$ variam com a espécie vegetal, assim Ciferri, no seu magnífico tratado de Fisiologia Vegetal, à pag. 442, diz "aparentemente, só uma pequena porção de $\mathrm{Mg}$ é suficiente para satisfazer as necessidades da planta, porque o elemento se transloca com facilidade, podendo ser usado muitas vezes como "carrier". O feijão, por exemplo, pode passar todo o seu ciclo graças ao $\mathrm{Mg}$ armazenado na semente".

Por outro lado, os sintomas de necrose aparecem sempre, nas condições de campo aos 20-24 meses e Alvim os constatou, após 12-14 meses (o ensaio teve a duração de 18 meses), admitindo, pois, que, nas condições de cultura artificial em solução nutritiva, a moléstia aparecesse mais cedo. Ainda assim discordamos pelo seguinte: Medina, à pág. 76 do seu trabalho "A necrose da base da folha do sisal", diz que "ela (a moléstia) inicia seu aparecimento em uma plantação sòmente nas folhas que atingiram um certo grau de maturidade; nunca a verificamos em folhas novas, que acabam de se destacar do broto central, nem, tampouco, nas completamente maduras. Atinge sòmente aquelas situadas em um ângulo de 45 a 75 graus com a horizontal"; aliás, Alvim transcreve êste trecho à pág. 230, de sua publicação. As manchas aparecem, em resumo, nas folhas do meio, nunca nas folhas novas do brôto central e nas de saia já bem amadurecidas. $O$ gráfico I dá uma idéia melhor da ocorrência, assim como as fotos 2 e 3 anexas do ensaio de campo da Secção e ainda as expostas por Medina no seu já citado trabalho (págs. 83 e 84).

Inicialmente, segundo nossas observações, aparece uma pequena mancha escura na parte inferior da base da folha; essa mancha vai se desenvolvendo, rodeia a base da folha, formando um verdadeiro anel negro ao redor da mesma, com 8 a $10 \mathrm{cms}$. de largura; a necrose determina a interrupção na circulação da seiva e a folha perde a sua turgescência, descolora-se um pouco, dobra-se na parte necrosada, tocando o chão com a extremidade; uma adubação potássica pode impedir o desenvolvimento da moléstia.

Também julgamos não ser o magnésio o causador da necrose, uma vez que o resto da folha atacada mantém uma côr verde intensa, idêntica a dos pés sadios e não se concebe carência 
ou ausência de $\mathrm{Mg}$ em folhas tão fortemente clorofiladas, visto que êsse elemento é primordial na formação das clorofilas, responsáveis pela côr verde das folhas.

As folhas adultas, quando nelas aparecem o "colarinho preto", medem de 70 a $90 \mathrm{cms}$.; em solução nutritiva, Alvim a verificou em folhas de 8 a $10 \mathrm{cms}$. (9 vezes menor). E' bem verdade, também, que as manchas aparecidas no ensaio sem potássio não se assemelham à necrose típica, porém, achamos que, no curto prazo de ano e meio, não houve o amadurecimento desejável das folhas para o aparecimento da moléstia e as necroses verificadas nada representam senão uma carência dos elementos ensaiados. Alvim, aliás, cita, também, no ensaio em solução nutritiva sem fósforo, ocorrência de necrose. No nosso campo, a ocorrência de colarinho preto nos tratamentos não potássicos é comum após 20-24 meses de cultura de mudas (rebentões) enviveiradas de 8 a 10 meses; no viveiro não houve aparecimento de manchas, embora não adubado com fertilizantes minerais.

Por outro lado, para êste estudo reputamos de importância capital as manchas apresentadas, visíveis na fig. 6 (reprodução inclusa) do seu trabalho que se acham localizadas não apenas na metade ou têrço inferior, mas na metade superior também. isto é, em quase tôda a extensão da folha e não só na base; não descreve Alvim e também não se nota na fotografia o estreitamento basal característico da necrose da base da folha como se pode ver na foto 3 desta comunicação e nas fotos do trabalho de Medina. Além disso, as manchas escuras visíveis na fig. 6 (reprodução inclusa) são longitudinais em quase tôda a extensão da folha, enquanto que o "colarinho preto" é transversal e localiza-se na base da folha no têrço inferior, ocupando uma faixa de 8 a $10 \mathrm{cms}$.; pois bem, 8 a $10 \mathrm{cms}$. em uma folha de 70 a $90 \mathrm{cms}$. representam $1 / 10$ da área, ao passo que Alvim, ao que parece, no ensaio sem magnésio com folhas de 17 a $19 \mathrm{cms}$. exibe manchas compridas no meio da folha de extensão igual a $1 / 2$ ou 1/3 da área total. Seria desejável que Alvim exibisse fotos maiores, coloridas, com folhas isoladas ou mesmo desenho mostrando melhor as manchas.

Ao ler o trabalho de Alvim, a 1a. idéia que nos ocorreu foi fazer um pequeno ensaio de campo, para verificar a cura da moléstia ou, então, o não aparecimento da mesma em cultura de 24 meses, onde se ia proceder ao $1^{\circ}$. corte. Nestas condições, separámos 200 pés de uma cultura daquela idade e organizámos o seguinte plano: 
Trat. n. $1-50$ pés adubação N-P - sem $\mathrm{K}$ com 100g de MgSO4 Trat. n. $2-50$ pés adubação N-P - sem $\mathrm{K}$ com $50 \mathrm{~g}$ de $\mathrm{MgSO} 4$ Trat. n. $3-50$ pés adubação N-P - sem $\mathrm{K}$ e sem $\mathrm{Mg}$ Trat. n. $4-50$ pés adubação N-P-K (sendo o potássio na for(ma de $\mathrm{KSO} 4$ droga pu(ra isenta de magnésio (para não levar êsse cor(po como impureza

Foram feitas 2 aplicações : uma, na sêca, e outra, após as primeiras chuvas e o resultado foi significativo : ocorrência da mancha nos tratamentos magnesianos sem K (1 e 2) e ainda o contrôle N-P sem K e Mg (3); a maior ocorrência foi na dose de $100 \mathrm{~g}$., isto é, a dose forte de $\mathrm{Mg}$ deierminou um maior aparecimento da moléstia. No tratamento $4-\mathrm{N}-\mathrm{P}-\mathrm{K}$ não houve uma só folha de um único pé. Com o uso de K2SO4, droga pu$\mathrm{ra}$, eliminou-se o inconveniente de ajuntar $\mathrm{Mg}$ como impureza como cita Alvim à pag. 230 "Medina (1943), etc.". Quando à hipotese aventada, de que o potássio, por dupla troca, poria magnésio ao dispôr da planta, embora viável, julgamos que, se no ensaio feito em Piracicaba, 50 e $100 \mathrm{~g}$. de MgSO4 nada fizeram, sal solúvel como é, usado também por Alvim na solução de Hoagland, não acreditamos que o $\mathrm{Mg}$ do solo resolvesse a questão. A análise do solo do campo da Seç̧ão Técnica de “Química Agrícola" revelou regular teor nesse elemento. Pelos quadros I, II, III, IV e V do ensaio que a Secção leva a efeito desde Dezembro de 1944 pode-se notar (observar o V) que (a) a maior ocorrência se verificou no tratamento 8 (só calcio); (b) que os tratamentos não potássicos, sem distinção, tiveram apreciável ocorrência; (c) que apenas 9 folhas (4 pés -1 folha num, 4 folhas noutro, 2 e 1 folhas noutros dois), quantidade desprezível, considerando-se que nos 3 cortes do ensaio de 900 pés foram colhidas perto de 8.000 folhas; apareceram em tratamentos potássicos, o que pode ser explicado pela variação individual a que está sujeita a planta, como pelo arrastamento, erosão ou outro fator qualquer que inibiu o aproveitamento do potássio; (d) nos tratamentos 1 e 2, com $\mathrm{K}$, porém, sem $\mathrm{Mg}$, não houve uma única ocorrência, enquanto que a adubação mais completa, tratamento $\mathrm{n}$. 7 , com $\mathrm{Mg}$, houve pequena ocorrência de 8 folhas. 


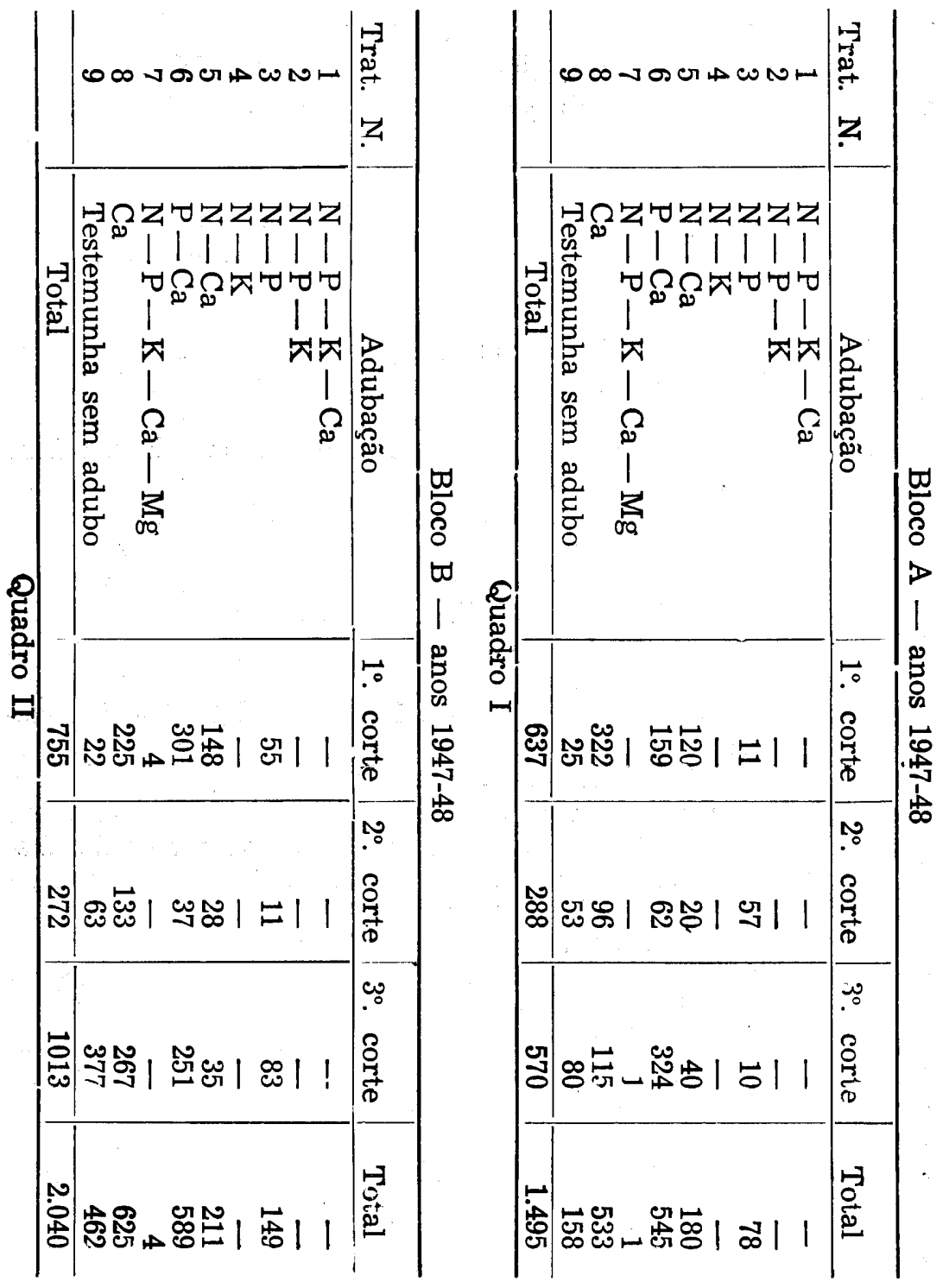




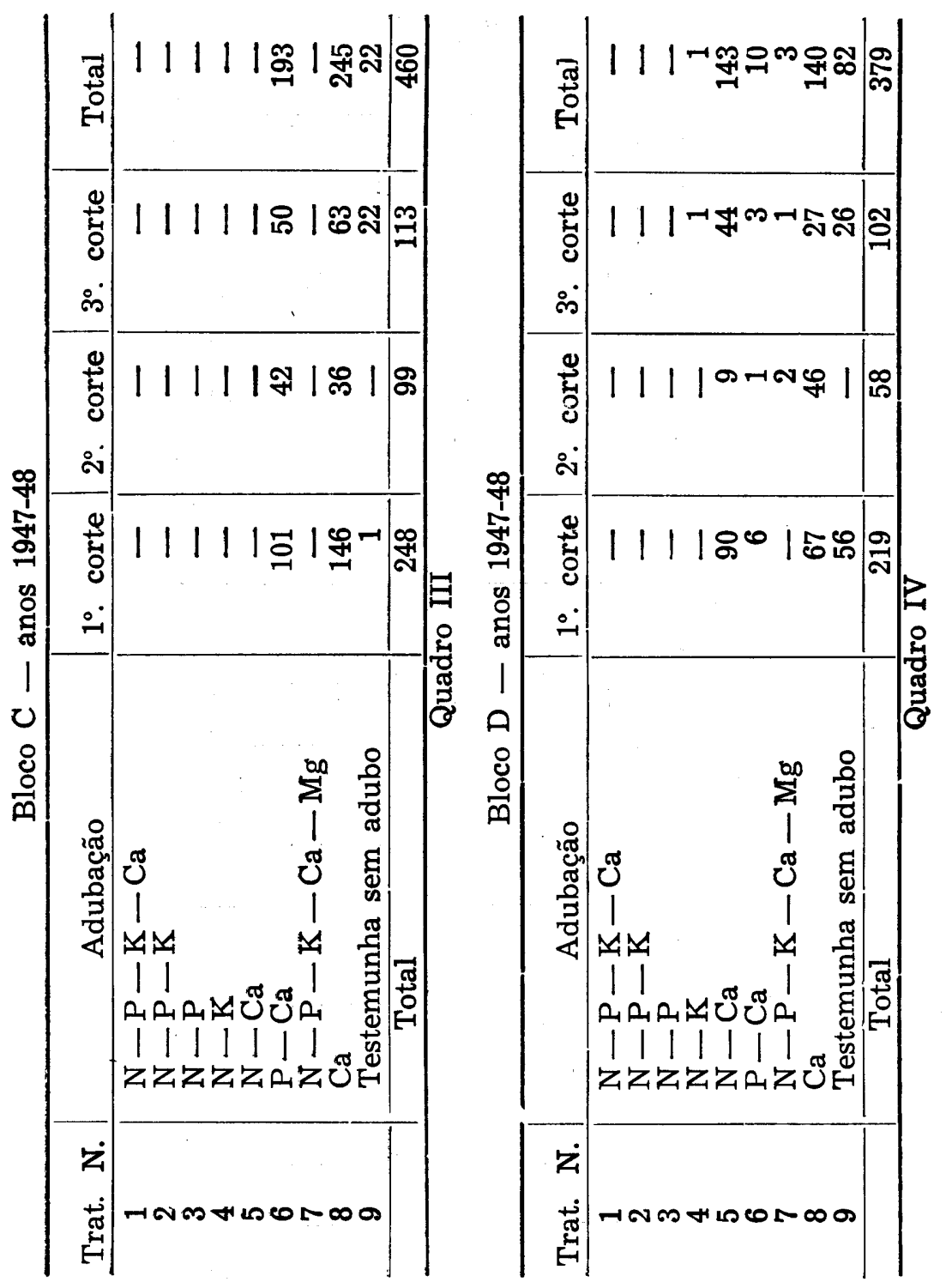




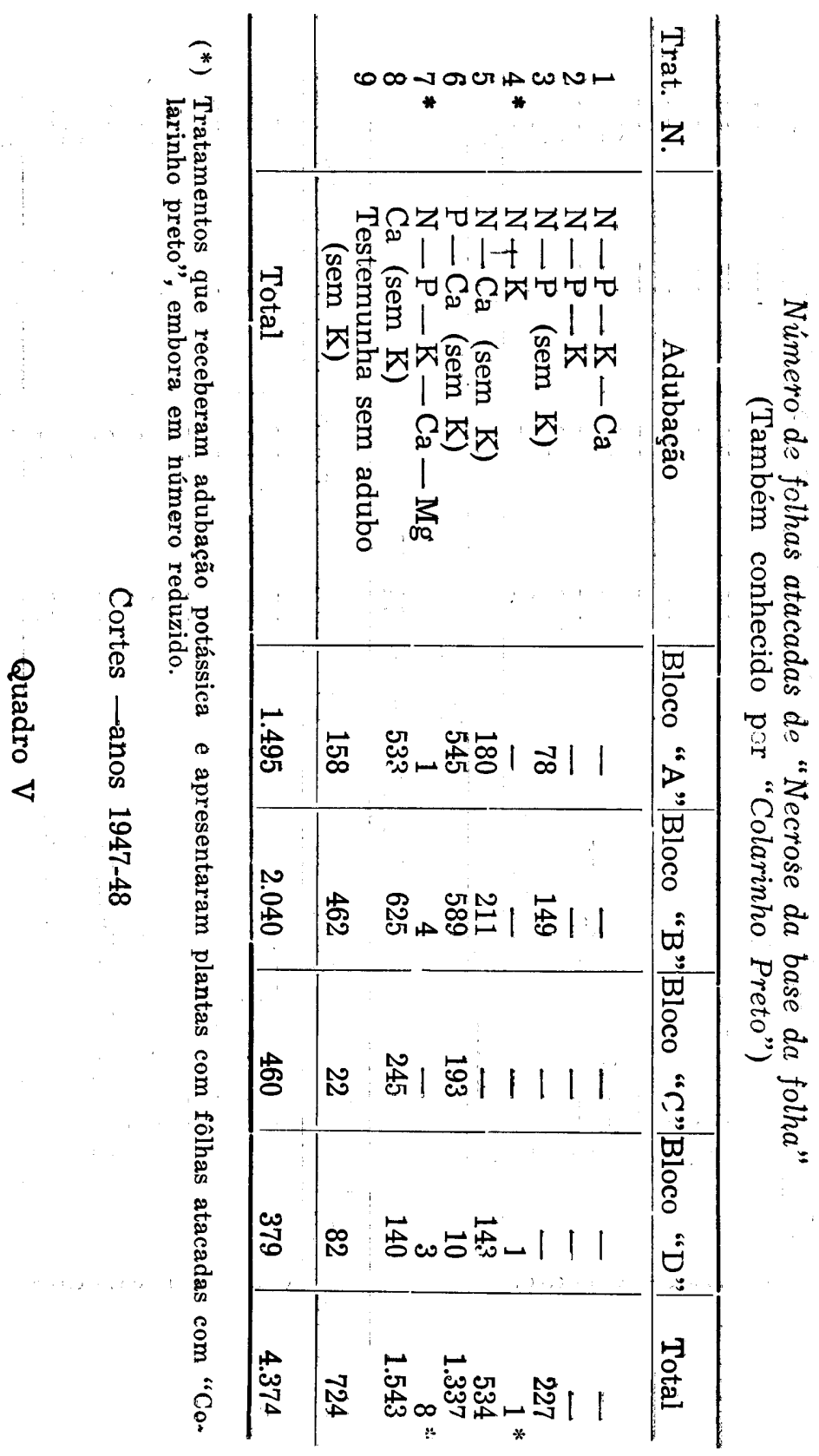


Corroborando o nenhum efeito do magnésio para evitar o aparecimento da necrose da base da folha, transcreve o trecho contido na página 183 do "Department of Agriculture, Annual Report 1948, Parts I, II and III, Nairobi, p. IV + 228, 1950", relacionado com o assunto da necrose da base da folha do sisal : "Banding disease. - In February, 1946, a manurial trial was laid out on an state in the Fort Hall district to find ways and means of combating banding disease. The manurial applications were lime, magnesite and dolomite at the rates of one and two tons per acre. After two years no improvement resulted from the applications of these fertilizers. Samples of leaves and soil were sent to the Macaulay Institute in Aberdeen where it was found that the potash contet of the soil and leaves from healthy areas was about five times as much as that from unhealthy areas. The assumption that the disease was due to a potash deficiency in the soil was confirmed by manurial experiments in Tanganyka". (por gentileza do colega J. C. Medina).

Não poderia o autor concluir que a verdadeira causa é falta de magnésio e não potássio, sem a prova experimental no campo. O autor faz referência a ensaios de campo iniciados em Dezembro de 1949, e, como até agora não tornou públicos os resultados (18 meses), é pouco provável que tenha obtido confirmação do observado, em solução nutritiva. Com as devidas reservas, em forma de observação preliminar, J. C. Medina comunicou ao autor desta crítica que "a Secção de Fisiologia, com Coaracy M. Francò, em colaboração com J. C. Medina, está procedendo a ensaios com solução nutritiva nos mesmos moldes de Alvim e as primeiras observações não confirmam ser o $\mathrm{Mg}$ o responsável pela ncrose. Alvim, também, à pág. 288, descrevendo os sintomas que constatou na solução sem magnésio, diz "manchas escuras" (quase pretas); pois bem, o "colarinho preto" é bem negro azeviche, segundo outros.

O alcance da observação de Alvim seria de interêsse capital para a nossa economia, uma vez que a adubação potásssica indispensável ao sisal seria reduzida ao mínimo e substituida por uma muitissimo mais barata e nacional ou seja a adubação magnesiana com dolomite. Aliás, a êste respeito, infelizmente, já se preconizou, supomos que sem resultado, o emprêgo de dolomite nas culturas de sisal do Estado da Paraíba, conforme se pode verificar no artigo redatorial da revista Engenharia "Mineração de Metalurgia", vol. XV, n. 90 - Março-Abril - 
1951, à pág. 288 que transcrevemos com a devida vênia na integra "A carência de magnésio é responsável pela necrose das folhas do sisal" - o Dr. Paulo de T. Alvim, professor de Botânica da Escola Superior de Agricultura de Viçosa, publicou no número de Janeiro-Junho de 1950 da revista "Ceres", interessante trabalho sôbre as deficiências minerais no sisal (Agave sisalana Perrine), planta que vem sendo cultivada no Brasil, especialmente em São Paulo, Baía, Minas Gerais e Paraíba, para a produção de fibra. Procurando estudar a causa da necrose na base das folhas do sisal - que J. C. Medina atribuiu à deficiência de potássio no solo, e Adelmo A. Machado à falta de cálcio - procedeu o Dr. Alvim à cultura da planta, em laboratório, em soluções completas e em meios desfalcados, respectivamente, de potássio, fósforo, cálcio, nitrogênio, magnésio, enxofre, ferro e boro. Chegou, assim, ao resultado de que a carência de cada um dos elementos boro, nitrogênio, ferro e magnésio provocavam a redução do tamanho da planta até um quinto do pêso da planta plenamente alimentada, enquanto a deficiência do magnésio acentuadamente provocava a necrose das folhas.

A carência de fósforo foi a menos nociva, seguida do potássio. Como a doença mencionada é comum nas culturas de sisal da Paraíba, algumas localizadas no topo dos chapadões da Borborema, como em derredor de Piçui, em solo arenoso, residual do capeamento arenítico, seria aconselhável adubar o ágave com dolomita moida, mineral que ocorre em muitas localidades da Paraíba (Piçuí, Cajazeiras, Patos, etc.)".

Se o trabalho tivesse sido publicado como nota prévia ou observação preliminar e dado conclusões definitivas, só após o ensaio de campo que iniciou em Dezembro de 1949 (pág. 231) e cujos resultados ignoramos se foi dado à publicidade, uma vez que decorreram 18 meses, ter-se-ia evitado uma propaganda que pode levar os cultivadores de sisal da Paraíba e de todo o país a gasto inútil e desilusão nos resultados. A publicação de dados parciais, não definitivos, podem determinar casos como êste, que, aplicados na prática, provocam prejuizos aos interessados. A Secção vai instalar, dentro em breve, alguns ensaios em solução nutritiva e incluirá um de sisal, trabalhando com vasos grandes (de barro vidrado, esmaltado a fogo), substrato de areia pura lavada durante 36 meses, se possível, para dizer a ultima palavra sôbre o palpitante tema aqui abordado, corroborando o nosso ponto de vista ou o de Alvim, 
ou, ainda, uma associação de ambos, talvez uma questão $\mathrm{K} / \mathrm{Mg}$ nos solos. Entretanto, julgamos que Alvim, a despeito de bem executar o seu trabalho, e bem intencionado como é, cometeu um equívoco confudindo uma necrose comum com a "necrose típica da base da folha do sisal".

\section{BIBLIOGRAFIA CONSULTADA}

ALVIM, PAULO DE T. (Ph. D.) .1950) - Deficiências minerais em sisal e a necrose da base das folhas - Ceres - 46: 222-232.

COURY, T., G. RANZANI, E. J. KIEHL, E. MALAVOLTA, F. P. GOMES et V. L. FAGUNDES. 1951 - Essai de fertilization minerale sur le sisal (Agave sisalana Perrine). Nóta prévia apresentada ao $2^{\circ}$. Congresso Mundial de Adubos Químicos - Outubro - Roma.

CUSTODIO, TEODORO P. 1943 - El Henequen, sizal y otros agaves similares - Boletin de la Direccion de Agricultura 48,51 : $43-172$.

FAGUNDES, VIRGILIO LOPES. 1947 - A cultura do sisal no Brasil - Colheitas e Mercados - Bol. Inf. D.P.V. - 11, 12: $3-7$.

GLOVER, J.. 1939 - The root system of Agave sisalana in Certain East African soils. Emp. Jour. Exp. Agric. 7: 11-20. 1939.

LOCCK, G. W. 1935 - Programe of an agronomic investigation of sizal. Planter 4: 12-13; (2) : 6-7, 14-15.

MACHADO, ADELMO A. 1948 - As doenças do Agave na Paraíba - Publ. Escola de Agronomia do Nordeste.

MEDINA, J. C. 1942 - Notas sôbre a cultura e exploração do sisal - Rev. "O solo" 3: 81-121. 1943 - A necrose de base da folha do sisal - Bragantia 3: 73-84. 
1946 - A influência do espaçamento sôbre o ciclo vegetativo do sisal - Bragantia 6: 111-117.

91-108. 1948 - A experimentação do sisal - Bragantia 8: 1951 - Comunicação particular - Carta 31-1-1951.

NUTMAN, J. 1931 - The field for sisal research in East Africa. Bull. Imp. Inst. 29: 299-307.

SAMPAIO, RAPHAEL SALLES. 1951 - O cultivo e a Industrialização do Sisal no E. S. Paulo e as possibilidades de produção das Fibras Téxteis no Brasil — Rev. Soc. Rural Brasileira - Vários Ns.

SMITH, HAMEL. 1936 - Sizal, production and preparation.

TIBYRIÇA, IRVINO W. 1940 - Sisal. Publ. S. I. A. Min. Agricultura D. N. Prod. Vegetal. 


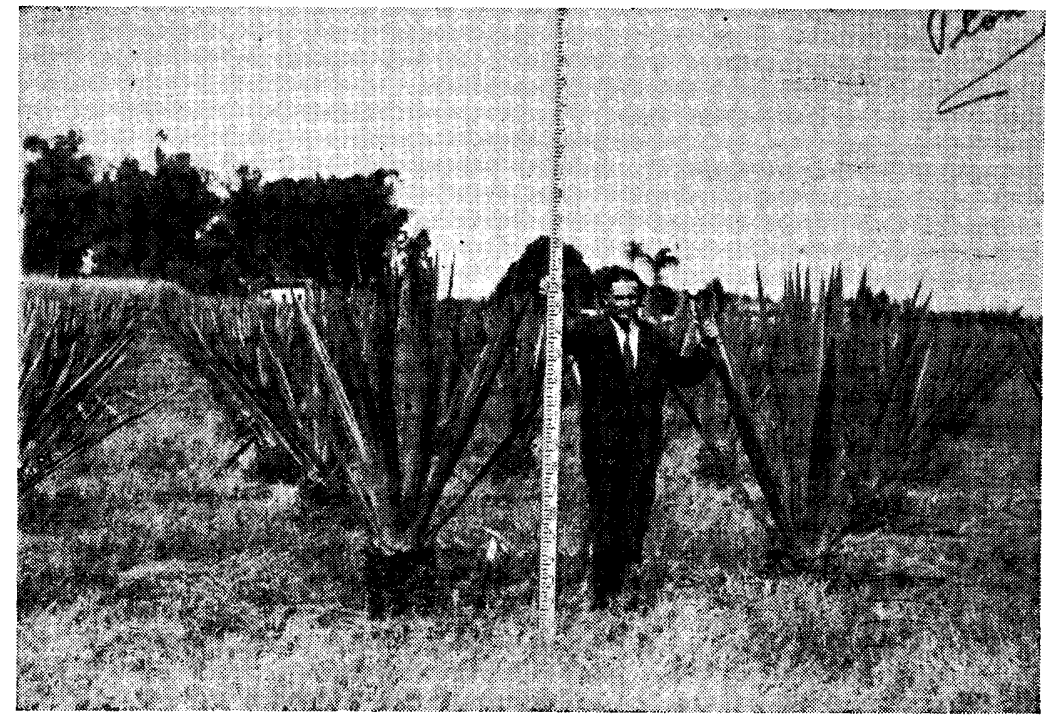

Pés sadios $(\mathrm{N}-\mathrm{P}-\mathrm{K})$ - sem ocorrência da necrose

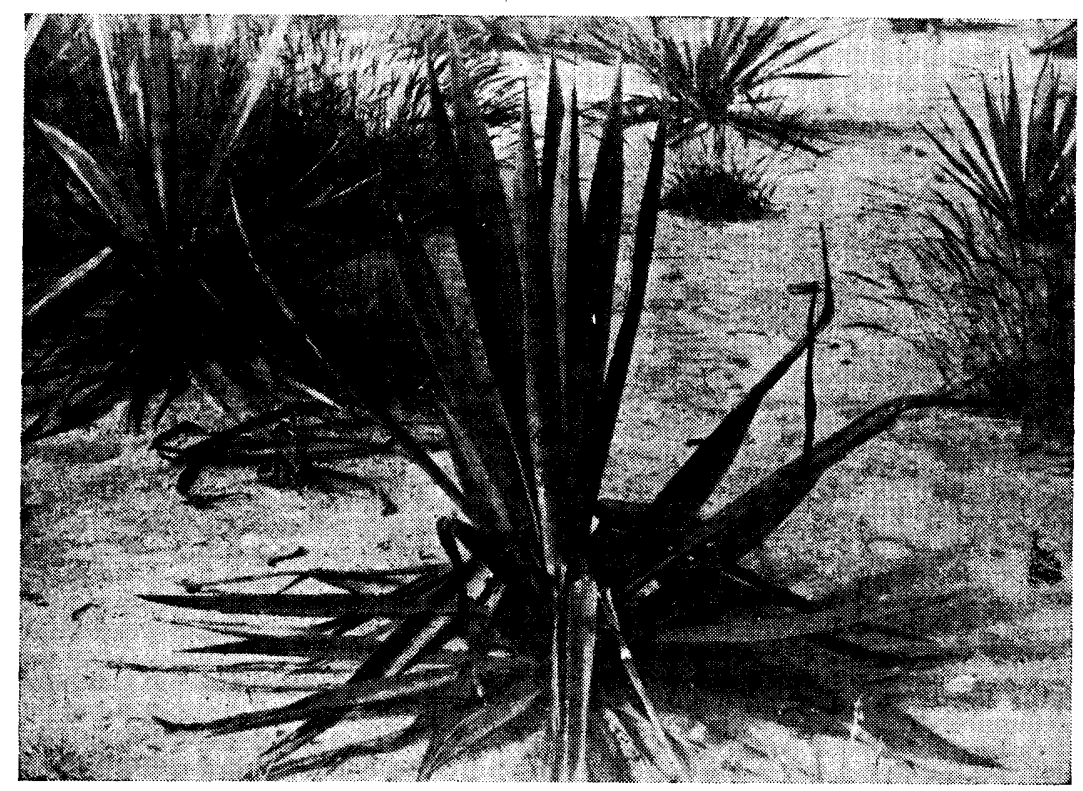

O calcareo empregado tinha $8,7 \%$ de $\mathrm{MgO}$

Tratamento $\mathrm{Ca}$ - ocorrência da necrose

Folhas atacadas situadas num ângulo de 45 a $75 "$ com a horizontal Não se vê na saia, nem no brôto central 


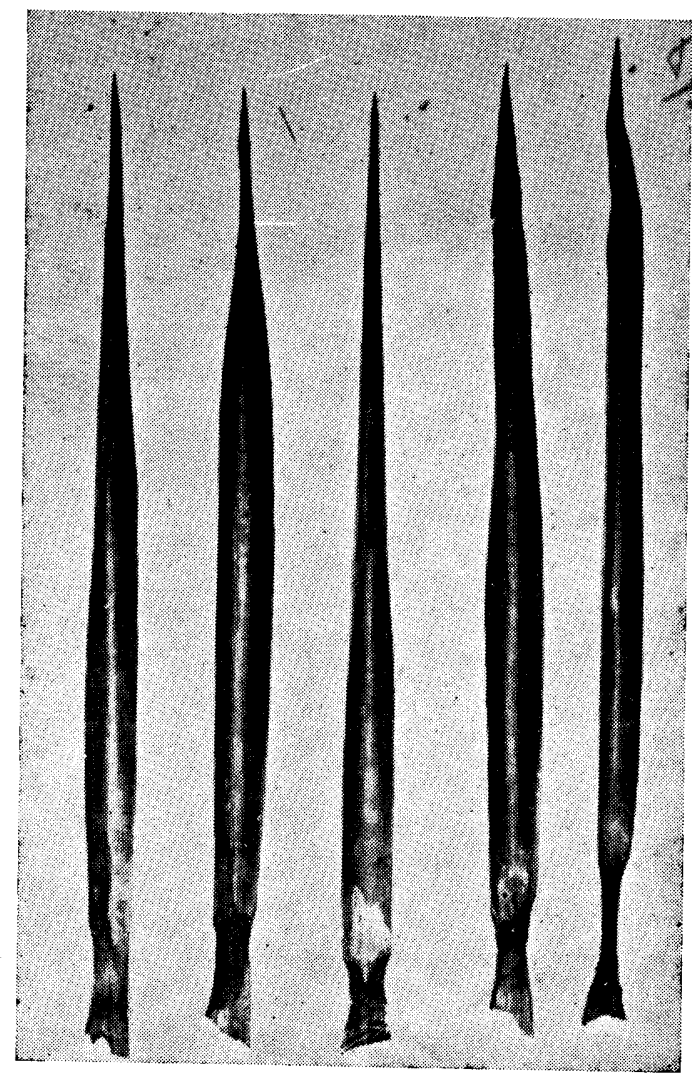

Folhas isoladas com "colarinho preto" (necrose) Atinge 8 a $10 \mathrm{cms}$. de área (1/10 da folha toda) 


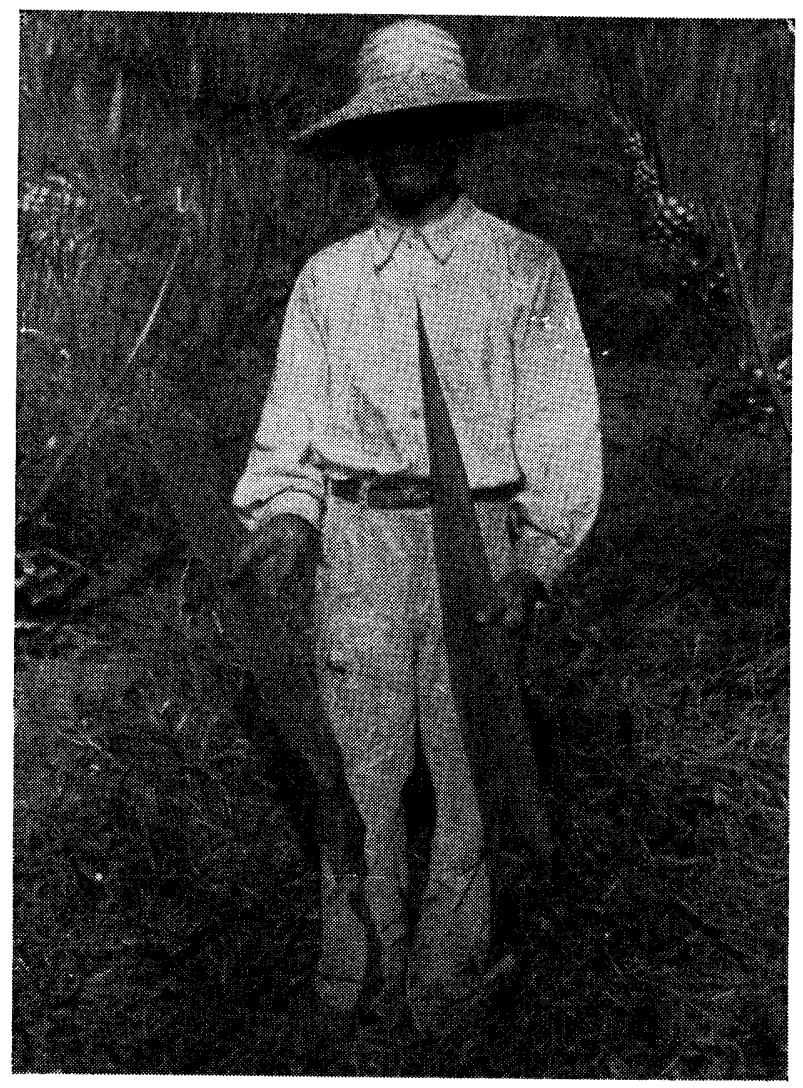

Duas folhas recem cortadas atacadas da necrose

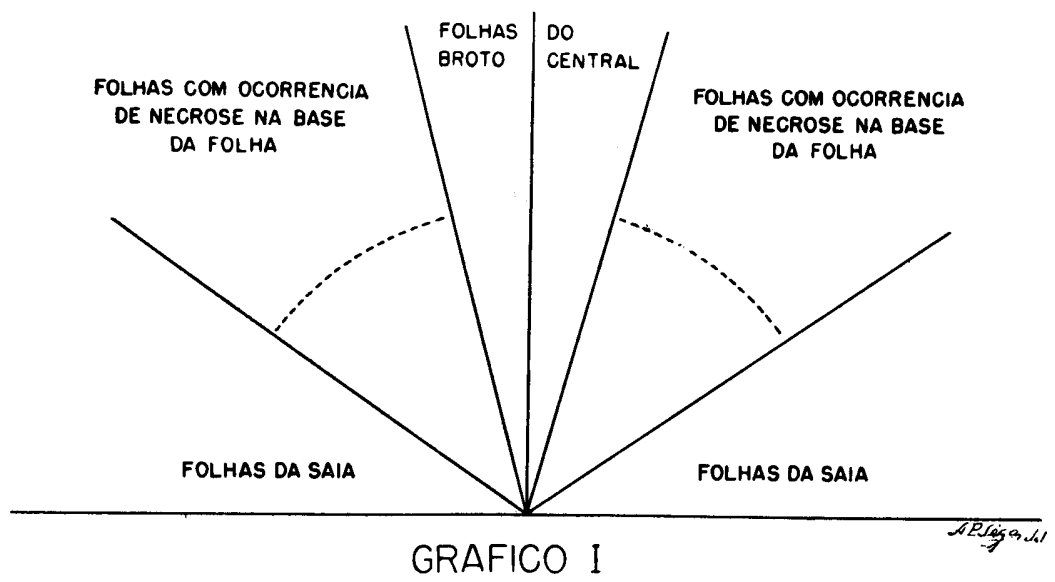




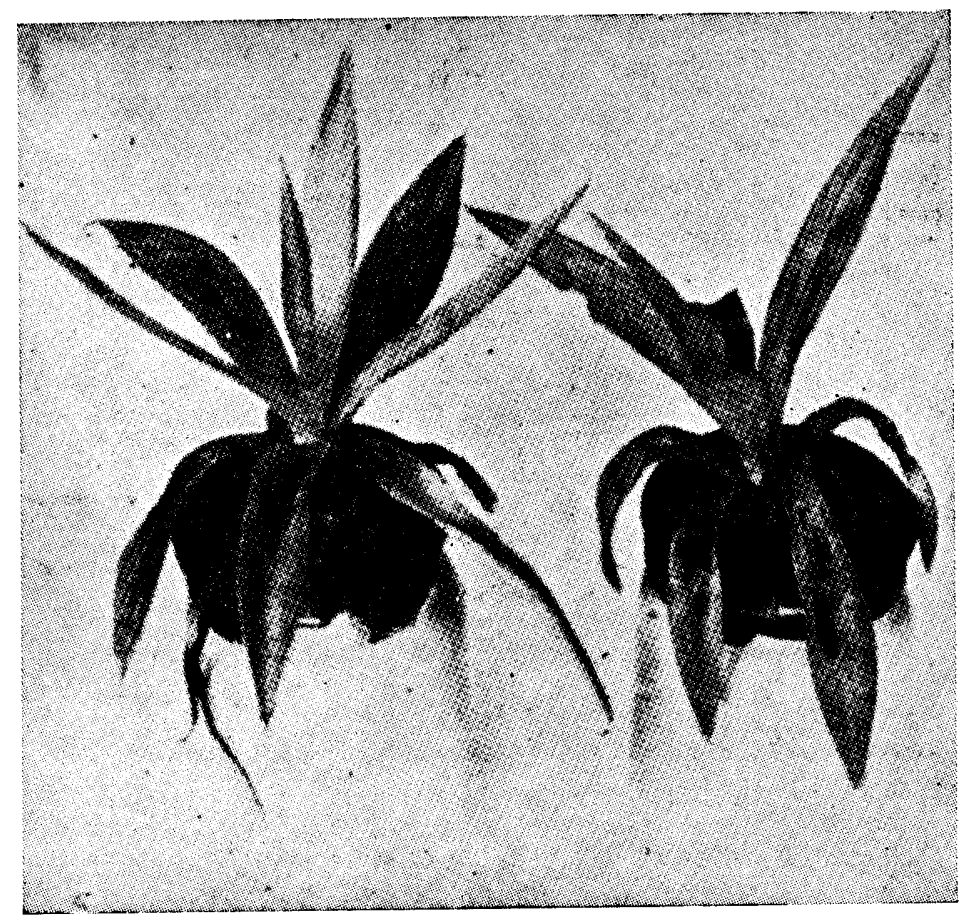

Reprodução da fig. 6 do trabalho original de Alvim 